\title{
New Normal in the Construction Industry a Covid-19 Effect
}

\author{
Amor Judith A. CABANESAS ${ }^{1}$, Romualdo M. CABANESAS ${ }^{2}$, Jay-ar M. PADILLA ${ }^{3}$, Rick Donald S. \\ MANZON $^{4}$, Salvador A. LORIA. Jr $^{5}$
}

1,2,3,4,5Nueva Ecija University of Science and Technology Gen. Tinio Street, Cabanatuan City 3100

\begin{abstract}
Construction is one of the oldest and major industries in the world that makes substantial contribution to the national economy and provides employment to a great number of individuals. In the early part of year 2020, COVID-19 pandemic arises that has turned into a worldwide catastrophe, evolving at high speed and scale. The impacts on the construction industry have been sudden and wide-ranging. This outbreak changes the usual daily activity and 'The New Normal' is introduced. Construction companies are moving forward, with strict regulations that end up as the new normal for the industry. This study explored the adaption to this new normal in Nueva Ecija, Philippines and seeks out if there's a relationship between adaption to new safety protocols and the category also the number of workers in a company. Survey was done for data collection. SPSS 25 software was used for data analysis. Result reveals that although the percentage of adaption to new normal is great, still there are areas that needs improvement. In addition, the company's category and the number manpower does indeed has correlation on the adaption to new normal. This study is essential to ensure responsible, healthy, safe operations, and serve as protection of workers.
\end{abstract}

KEYWORDS: COVID -19, Construction Industry, New Normal, Pandemic

\section{INTRODUCTION}

Construction is one of the oldest and one of the major industries in the world that makes a substantial contribution to the national economy and provides employment to a great number of individuals.

In the early part of the year 2020, the COVID-19 pandemic arises that has turned into a worldwide catastrophe, evolving at high speed and scale. No industry is immune to this crisis. The impacts on the construction industry have been sudden and wide-ranging. This outbreak changes the usual daily activity of people and what we know now as 'The New Normal'. Construction companies are moving forward now, with strict regulations enforced by the government and local authorities, to ensure responsible, healthy, and safe operations under COVID19 and safeguard the survival of the business as well as the protection of workers. These new regulatory standards end up sticking around as the new normal for the industry.

The study explored the new normal in the construction industry in the province of Nueva Ecija. Furthermore, the study seeks out if there is a significant relationship between the adaption of new safety protocols and the category of the company also the number of workers.

\section{OBJECTIVES}

\section{A. General Objective}

The objective of this study is to explore the new normal in the construction industry in the province of Nueva Ecija.

\section{B. Specific Objective}

1. Determine the percentage of construction companies that adapt the safety protocols implemented by the Construction Industry Authority of the Philippines in terms of material deliveries, manpower, machinery, and money.

2. Determine if there is a significant relationship in the adaption of safety protocols and the category of the construction company (Quadruple A, Triple A, Double A, etc.).

3. Determine if there is a significant relationship between the adaption of safety protocols and the number of their manpower.

\section{METHODOLOY}

Figure 3.1 shows the cycle of the research study. The inputs are the Socio Demographic of a Company and the Safety Protocols and Guidelines. The data are collected and tabulated. For the relationship, data are analysed by Pearson's Correlation using SPSS and the output determines the percentage of construction companies adapting the new normal, the significant relationship in the adaption of safety protocols and the category of the construction company significant relationship in the adaption of safety protocols and the number of their manpower. 


\section{INPUT}

Socio Demographic of a Company

Safety Protocols and Guidelines

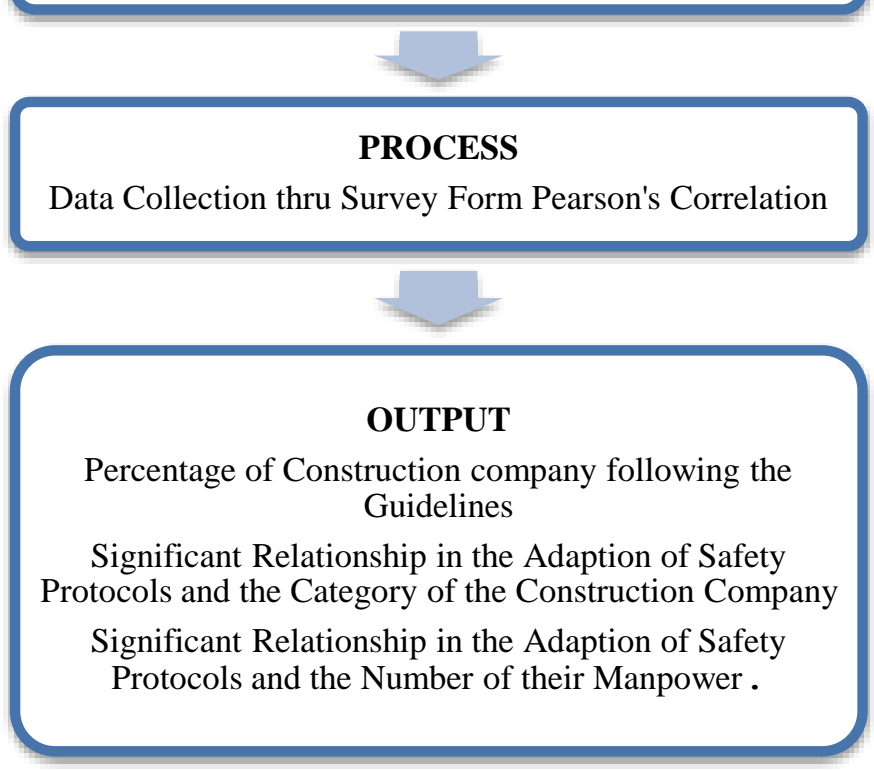

Figure 3-1. Research Flow

\section{RESULTS AND DISCUSSION}

The data fetched from the survey is from the respondents across the province of Nueva Ecija. It was analyzed using descriptive statistics. Figure 4-1 presents the distribution of these respondents based on their district. The highest number of participants is from District 3 with $43.33 \%$, followed by District 2 with $23.33 \%$, District 4 and District 1 with $16.67 \%$.

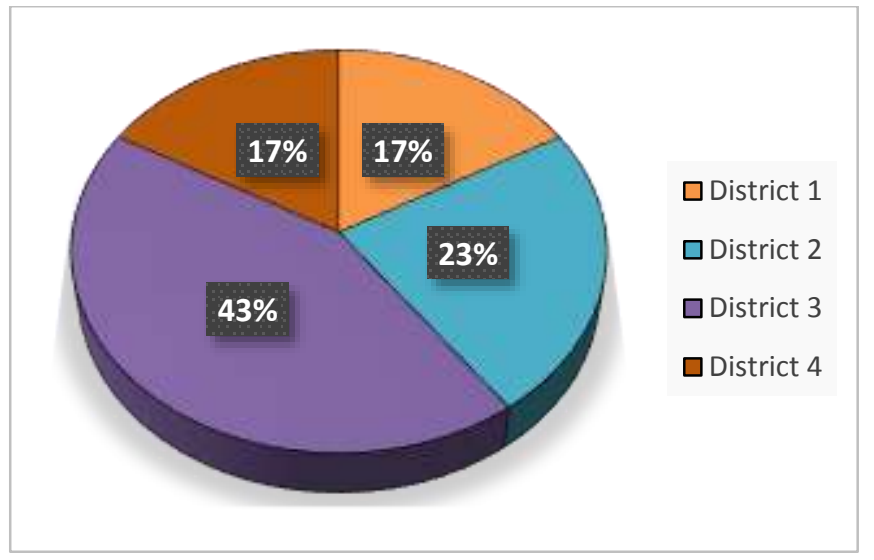

Figure 4-1. Respondents Location

The distribution of respondents in Table IV-1 shows that the participants are skilled professionals considering their designation in their company. Over $90 \%$ of the participants are, directly working at site projects as such their responses regarding the study context are deemed essential and valid. Moreover, their company's category and the number of manpower are of the study interest. The respondents are highly experienced in the industry, with over $70 \%$ of them having more than 5 to 10 years of industry experience. On the other hand, the respondents are generally from Triple A to DTI Registered only there are no Quadruple A company registered at Nueva Ecija.

Table IV-1. Shows the Demographic of the Respondents.

\begin{tabular}{|c|c|c|c|}
\hline & Description & No. & Percentage \\
\hline \multirow{4}{*}{$\begin{array}{l}\text { Number of } \\
\text { Respondent }\end{array}$} & District 1 & 5 & $16.67 \%$ \\
\hline & District 2 & 7 & $23.33 \%$ \\
\hline & District 3 & 13 & $43.33 \%$ \\
\hline & District 4 & 5 & $16.67 \%$ \\
\hline \multirow{5}{*}{$\begin{array}{l}\text { Respondents } \\
\text { Company } \\
\text { Designation }\end{array}$} & Project Manager & 8 & $26.67 \%$ \\
\hline & Project Engineer & 9 & $30.00 \%$ \\
\hline & Safety Engineer & 1 & $3.33 \%$ \\
\hline & Site Engineer & 10 & $33.33 \%$ \\
\hline & Office Engineer & 2 & $6.67 \%$ \\
\hline \multirow{8}{*}{$\begin{array}{l}\text { Respondent } \\
\text { Company's } \\
\text { Category }\end{array}$} & Triple A & 7 & $23.33 \%$ \\
\hline & Double A & 4 & $13.33 \%$ \\
\hline & Single A & 3 & $10.00 \%$ \\
\hline & $\mathrm{B}$ & 7 & $23.33 \%$ \\
\hline & $\mathrm{C}$ & 2 & $6.67 \%$ \\
\hline & $\mathrm{D}$ & 2 & $6.67 \%$ \\
\hline & E/Trade & 1 & $3.33 \%$ \\
\hline & $\begin{array}{l}\text { DTI registerer } \\
\text { only }\end{array}$ & 4 & $13.33 \%$ \\
\hline \multirow{6}{*}{$\begin{array}{l}\text { Number } \\
\text { Manpower }\end{array}$} & $1-30$ & 5 & $16.67 \%$ \\
\hline & $31-60$ & 8 & $26.67 \%$ \\
\hline & $61-90$ & 6 & $20.00 \%$ \\
\hline & $91-120$ & 2 & $6.67 \%$ \\
\hline & $121-150$ & 5 & $16.67 \%$ \\
\hline & $>150$ & 4 & $13.33 \%$ \\
\hline \multirow{3}{*}{$\begin{array}{ll}\text { Number } & \text { of } \\
\text { years } & \text { of } \\
\text { Experience } & \end{array}$} & $5-10$ years & 22 & $73.33 \%$ \\
\hline & $11-15$ years & 6 & $20.00 \%$ \\
\hline & $>15$ years & 2 & $6.67 \%$ \\
\hline
\end{tabular}

A reliability test is conducted to discover an internal consistency of the items and the scale used. In this way, Cronbach's alpha is used for examining the reliability, and relates with George and Mallery's (2003) adequacy. Any coefficient of Cronbach's alpha that is greater than 0.6 is considered acceptable. The Cronbach's alpha result of the 47 significant variables of this study (presented in Table IV-2) demonstrates a true and acceptable reliability of the inter-item and the scale of measurement.

Table IV-2. Reliability Alpha Value

Reliability Statistics

\begin{tabular}{|c|c|r|}
\hline $\begin{array}{c}\text { Cronbach's } \\
\text { Alpha }\end{array}$ & $\begin{array}{c}\text { Cronbach's } \\
\text { Alpha Based } \\
\text { on } \\
\text { Standardized } \\
\text { Items }\end{array}$ & N of Items \\
\hline .931 & .930 & 47 \\
\hline
\end{tabular}

Presented in Table IV-3, it was evident from participant's responses that over $95 \%$ of construction companies in Nueva 
Ecija already adapt the new normal guided by the safety protocol released by the Construction Industry Authority of the Philippines (CIAP).

The adaption to new normal is further subdivided into four (4) factors which are the
1. Material deliveries,
2. Manpower,
3. Machinery and
4. Money.

About $99 \%$ of contractors already adapt the new normal in terms of Money, followed by machinery with $97 \%$, then manpower with $94 \%$, and lastly the material deliveries, which is only $93 \%$.

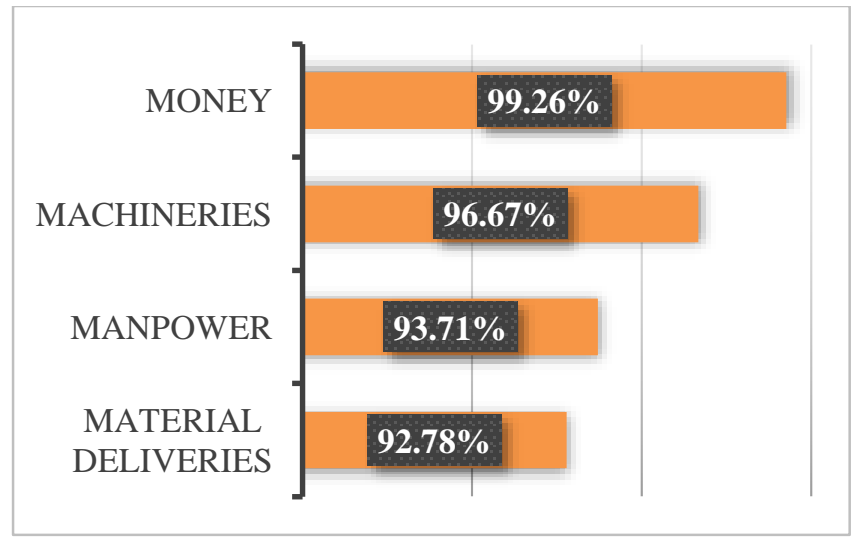

Figure 4-2 Percentage of Adaption to New Normal Based on Four Factors

Furthermore, based on the participants' responses, test scores are grouped per company's category as presented in figure 4-3 for the purpose of analysing if there is a significant relationship in the company's category and adaption to safety protocols using Pearson' Correlation.

Table IV-3. Participants Responses

\begin{tabular}{llll}
\hline & Options & Frequencies & Percentage \\
\hline $\begin{array}{l}\text { Material } \\
\text { Deliveries }\end{array}$ & Yes & 167 & $92.78 \%$ \\
& No & 13 & $7.22 \%$ \\
\hline Manpower & & & \\
Awareness and & Yes & 471 & $98.13 \%$ \\
Communication & No & 9 & $1.88 \%$ \\
\hline Clearing and & Yes & 171 & $95.00 \%$ \\
Return to Work & No & 9 & $5.00 \%$ \\
\hline Monitoring & Yes & 85 & $94.44 \%$ \\
& No & 5 & $5.56 \%$ \\
\hline Proper Work & Yes & 58 & $96.67 \%$ \\
Attire & No & 2 & $3.33 \%$ \\
\hline Social & Yes & 244 & $90.37 \%$ \\
Distancing and & & & \\
Precautionary & & & \\
Measures & No & 26 & $9.63 \%$ \\
\hline $\begin{array}{l}\text { Site Operations / } \\
\text { Construction }\end{array}$ & Yes & 279 & $93.00 \%$ \\
Work Site & & & \\
\hline & No & 21 & $7.00 \%$ \\
\hline
\end{tabular}

\begin{tabular}{|c|c|c|c|}
\hline Additional & Yes & 106 & $88.33 \%$ \\
\hline \multicolumn{4}{|l|}{ Guidelines for } \\
\hline \multicolumn{4}{|l|}{ Vertical and } \\
\hline \multicolumn{4}{|l|}{ Horizontal } \\
\hline Projects & No & 14 & $11.67 \%$ \\
\hline \multirow[t]{2}{*}{ Machinery } & Yes & 261 & $96.67 \%$ \\
\hline & No & 9 & $3.33 \%$ \\
\hline \multirow[t]{2}{*}{ Money } & Yes & 268 & $99.26 \%$ \\
\hline & No & 2 & $0.74 \%$ \\
\hline OVER & Yes & 2110 & $95.05 \%$ \\
\hline RESULT & No & 110 & $4.95 \%$ \\
\hline
\end{tabular}

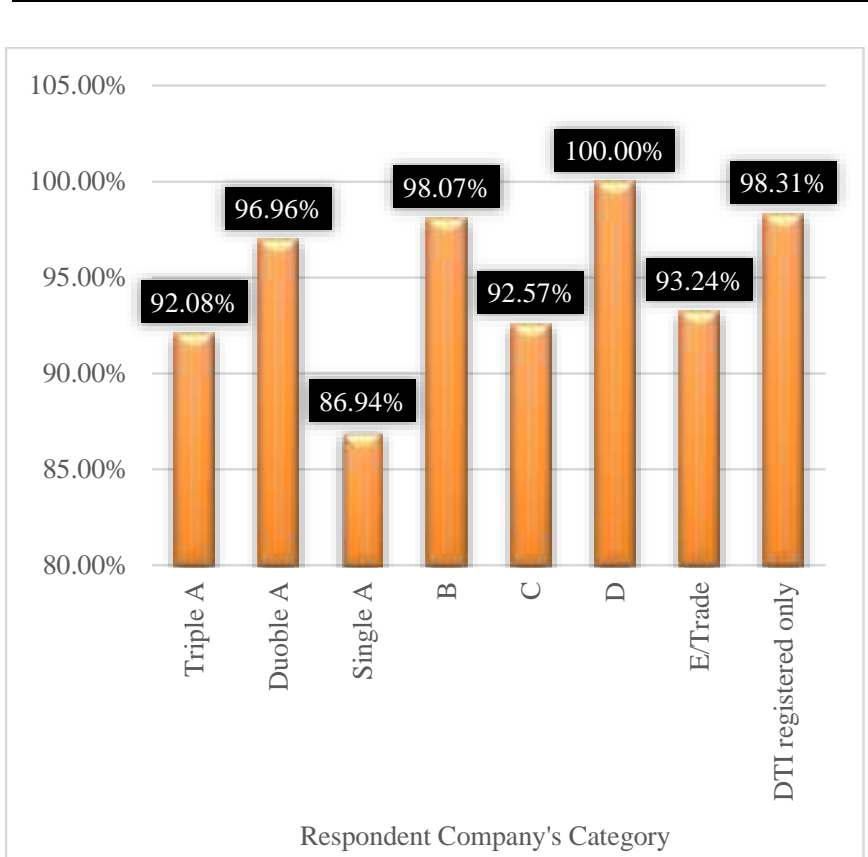

Figure 4-3 Percentage of Adaption to New Normal Based on Company's Category.

This statistical test ranges from -1 to +1 , where a result of -1 means that there is a negative correlation and a result of +1 means that there is a positive correlation. The correlation between two variables can be determined by the formula:

$$
r=\frac{\sum X_{i} Y_{i}-\left(\sum X_{i}\right)\left(Y_{i}\right)}{\sqrt{\left(\sum X_{i}^{2}-\left(X_{i}\right)^{2}\right)\left(\sum Y_{i}^{2}-\left(Y_{i}\right)^{2}\right)}}
$$

Table IV-4 Result of Pearson's Correlation Test on Company's

\begin{tabular}{|c|c|c|c|}
\hline \multicolumn{4}{|c|}{ Correlations } \\
\hline & & $\begin{array}{c}\text { Contractors_- } \\
\text { Category }\end{array}$ & Test_Scores \\
\hline \multirow[t]{3}{*}{ Contractors_Category } & Pearson Correlation & 1 & $.979^{11}$ \\
\hline & Sig. (2-tailed) & & .000 \\
\hline & N & 8 & 8 \\
\hline \multirow[t]{3}{*}{ Test_Scores } & Pearson Correlation & $.979^{11}$ & 1 \\
\hline & Sig. (2-tailed) & .000 & \\
\hline & $\mathrm{N}$ & 8 & 8 \\
\hline
\end{tabular}

**. Correlation is significant at the 0.01 level (2-tailed).

Category and Test Scores in Adaptability of Safety Protocols Using SPSS. 


\section{"New Normal in the Construction Industry a Covid-19 Effect"}

Based on the results of the study, the company's category has a very strong and positive relation to the adaption of safety protocol $\mathrm{r}=.979, \mathrm{p}<.01$.

In addition, based on the participants' responses, test scores are grouped per company's number of manpower as presented in figure 4.4 for the purpose of analysing if there is a significant relationship with the company's number of manpower and adaption to safety protocols using Pearson' Correlation.

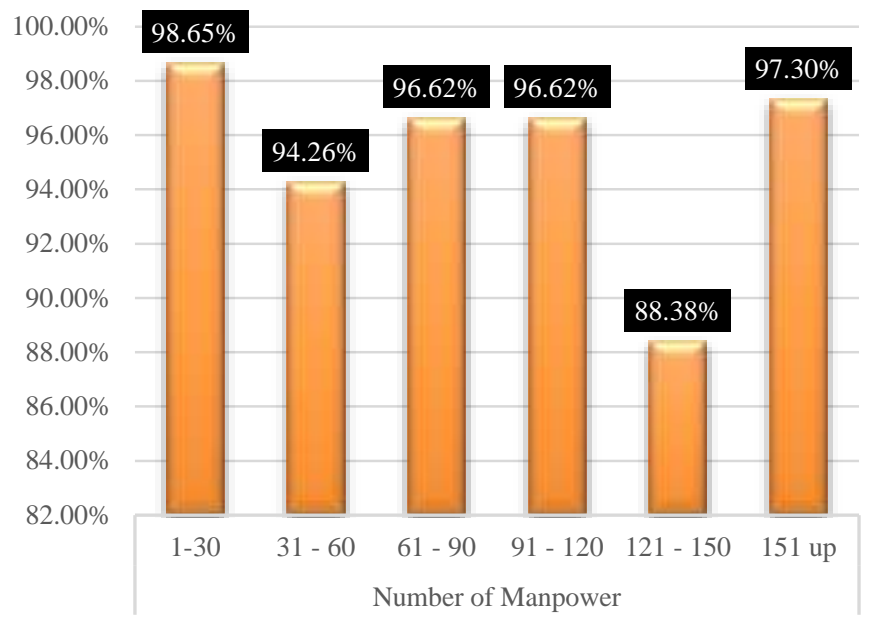

Figure 4-4 - Percentage of Adaption to New Normal Based on Company's Number of Manpower.

Table IV-5 Result of Pearson's Correlation Test on Company's Number of Manpower and Test Scores in Adaptability of Safety Protocols Using SPSS.

\section{Correlations}

\begin{tabular}{|ll|r|r|}
\hline & & $\begin{array}{c}\text { No. } \\
\text { ofManpower }\end{array}$ & Test_Score \\
\hline No.ofManpower & Pearson Correlation & 1 & $.995^{\prime \prime}$ \\
& Sig. (2-tailed) & & .000 \\
& N & 6 & 6 \\
\hline Test_Score & Pearson Correlation & $.995^{\prime \prime}$ & 1 \\
& Sig. (2-tailed) & .000 & \\
& N & 6 & 6 \\
\hline
\end{tabular}

${ }^{* *}$. Correlation is significant at the 0.01 level (2-tailed)

Based on the results of the study, the company's number of manpower has a very strong and positive relation to the adaption of safety protocol $\mathrm{r}=.995, \mathrm{p}<.01$.

\section{CONCLUSION}

Till date the whole world is suffering from COVID-19. Construction industry must keep moving forward with the new normal guided by the strict regulations enforced by the government and local authorities, to ensure responsible, healthy and safe operations for construction-related operations under COVID-19 and safeguard the survival of business as well as the protection of workers. In this study it shows that $95 \%$ of the construction companies in the province of Nueva Ecija already adapt the new normal which is beneficial to the manpower, the construction companies, the society and the government since it shows that safety protocols are adhered and this may prevent the spread of COVID-19 in the province. However, results discovered that there are still areas needs to be improved in adapting the new normal especially in dealing with material deliveries. By testing the adaption of new normal in Nueva Ecija, this study established that the category of the company as well as the number of the manpower does indeed have a significant relation on the adaption of new safety protocols. Large companies (Triple A to Single A) even small companies (B to DTI Registered Only) are able to adapt. Furthermore, the companies with smaller number of workers are able to follow the guidelines more since there are lesser manpower to monitor. Though, a $100 \%$ compliance is still needed for a safer workplace.

\section{REFERENCES}

1. McKinsey, 2020, Lund et al., 2020, COVID Response Center, available at:

https://www.mckinsey.com/about-us/covid-responsecenter/home

2. Fard Fini et al., 2018, Dynamic Programming Approach toward Optimization of Workforce Planning Decisions, ASCE Library, available at: https://ascelibrary.org/doi/pdf/10.1061/\%28ASCE\%29 CO.1943-7862.0001434

3. Gomar et al., 2002, Assignment and Allocation Optimization of Partially Multiskilled Workforce, ASCE Library, available at: https://ascelibrary.org/doi/abs/10.1061/(ASCE)07339364(2002)128:2(103)

4. Srour et al., 2006 Linear Programming Approach to Optimize Strategic Investment in the Construction Workforce, ASCE Library, available at: https://ascelibrary.org/doi/abs/10.1061/(ASCE)07339364(2006)132:11(1158

5. (ENR, 2020a) COVID-19: Confronting The New Normal, Engineering News Record, available at: https://www.enr.com/articles/49086-covid-19confronting-the-new-normal

6. Ayodele et al., 2020, Factors Affecting Workforce Turnover in the Construction Sector: A Systematic Review, ASCE Library, available at: https://ascelibrary.org/doi/abs/10.1061/\%28ASCE\%29 CO.1943-7862.0001725

7. Goodrum, 2004, Hispanic and Non-Hispanic Wage Differentials: Implications for United States Construction Industry, ASCE Library, available at: https://ascelibrary.org/doi/pdf/10.1061/\%28ASCE\%29 0733-9364\%282004\%29130\%3A4\%28552\%29

8. Jaselskis et al., 2008, Successful multi-national workforce integration program to improve construction site performance, Science Direct, available at: https://www.sciencedirect.com/science/article/abs/pii/ S0925753507001002 
9. Lee et al., 2020, Workforce development: understanding task-level job demands-resources, burnout, and performance in unskilled construction workers, Science Direct, available at:

https://www.sciencedirect.com/science/article/abs/pii/ S0925753519321885

10. Shen et al., 2015, Empirical Investigation of Factors Contributing to the Psychological Safety Climate on Construction Sites, ASCE Library, available at: https://ascelibrary.org/doi/abs/10.1061/(ASCE)CO.19 43-7862.0001021

11. Philippine Statistics Authority, Region III Central Luzon, available at:

http://rsso03.psa.gov.ph/article/construction-statisticsapproved-building-permits-central-luzon-first-quarter2020

12. de Bruin et al., 2020, Initial impacts of global risk mitigation measures taken during the combatting of the COVID-19 pandemic, Science Direct, available at: https://www.sciencedirect.com/science/article/pii/S09 2575352030103

13. Lindhout and Reniers, 2020, Reflecting on the safety zoo: Developing an integrated pandemics barrier model using early lessons from the Covid-19 pandemic, Science Direct, available at:

https://www.sciencedirect.com/science/article/pii/S09 25753520303040

14. Varotsos and Krapivin, 2020, A new model for the spread of COVID19 and the improvement of safety, Science Direct, available at:

https://www.sciencedirect.com/science/article/abs/pii/ S0925753520303593

15. Thomas and Horman, 2006, Fundamental Principles of Workforce Management, ASCE Library, available at: https://ascelibrary.org/doi/abs/10.1061/\%28ASCE\%29 0733-9364\%282006\%29132\%3A1\%2897\%29

16. WHO, 2020. Getting your workplace ready for COVID-19, available at:

https://www.who.int/docs/default-source/

coronaviruse/getting-workplace-ready-for-covid19.pdf

17. ARUP (2020), Mitigating COVID-19 risks during construction, A collection of illustrative approaches, available at:

https://www.google.com/search?q=Mitigating+COVI D-19+risks+during+construction+A+collection+of +illustrative+approaches\&rlz=1C1GCEU_enPH821P H821\&oq=Mitigating+COVID-19+risks++during+ construction $+\mathrm{A}+$ collection+of+illustrative+approache s\&aqs=chrome..69i57.441j0j9\&sourceid=chrome\&ie= UTF-8

18. AFRY (2020). How to prevent and mitigate the effects of Covid-19 at construction sites and production units?, available at: https://afry.com/en/insight/how-prevent-and-mitigateeffects-c ovid-19-construction-sites-and-productionunits?fbclid=IwAR3Qm_kN1BE3u1oy70zior_B9_3b9qQrNxpVW30Sca-ACFHp0t_8exZroo

19. Smith, S.F. (2020). Tips for Working Safely in Construction During the COVID-19 Pandemic, available at:

https://ohsonline.com/Articles/2020/12/01/Tips-forWorking-Safely-in-Construction-During-the-COVID19-

Pandemic.aspx?m=1\&fbclid=IwAR3Qm_kN1BE3u1o y70zior_B9-_3b9qQrNxpVW30Sca-

ACFHp0t_8exZroo\&Page $=4$

20. Hays, J.W. (2020). COVID-19's Impact on Construction: The New Normal, available at: https://www.jacksonkelly.com/construction-bulletinblog/covid-19s-impact-on-construction-the-newnormal?fbclid=IwAR37Msr84TmgVrrGgR1D50CNnJD0aezccW-vBC2U1N1Cfh1eiqSo0ZdDM

21. Construction Health and Safety NZ et al. (2020). COVID-19 Health and Safety Protocols for New Zealand Residential Construction Sites, available at: https://secure.chasnz.org/downloads/resources/COVI D19_Industry_Protocols_Residential_English_LEVE L3.pdf

22. Abadie, R. (2020). Five actions can help mitigate risks to infrastructure projects amid COVID-19, available at: https://www.pwc.com/gx/en/industries/capitalprojects-infrastructure/publications/infrastructurecovid19.html?fbclid=IwAR3LR2z0oa4aOLa6y9iiHg NmQj6KpWA_1jtYmBK4jRoQNmeUZCym2Z2INiI

23. Lloyd E. and Al-Ali L. (2020). COVID-19 and Construction Contracts: The Risks and Challenges Ahead, available at:

https://www.lexology.com/library/detail.aspx?g=b9db 54b5-2b89-42f7-894f-a2e85121115d\&fbclid =IwAR1t_NJEB-MSeovyvuN1_UH8PCMUv7w2gp1 EXJK0QmvPe2pvcbwBHs_IW_Ysecure.chasnz.org/d ownloads/resources/COVID19_Industry_Protocols_R esidential_English_LEVEL3.pdf

24. Philippines: WHO Coronavirus Disease (COVID-19) Dashboard, available at:

https://covid19.who.int/region/wpro/country/ph https://covid19.who.int/

25. Waxman, O. (2020). How Does a Pandemic End? Here's What We Can Learn From the 1918 Flu, available at: https://time.com/5894403/how-the-1918flu-pandemic-ended/

26. Ward, E. (2020). COVID-19 Impacts on the Construction Industry, available at: https://www.viewpoint.com/blog/covid-19-impactson-the-construction-industry 
27. Construction Industry Authority of the Philippines, Construction Guidelines for Project Implementation, available at: https://ciap.dti.gov.ph/content/constructionguidelines-project-implementation 